\title{
Textbook outcome after minimally invasive esophagectomy is an important prognostic indicator for predicting long-term oncological outcomes with locally advanced esophageal squamous cell carcinoma
}

\author{
Shao-Jun Xu ${ }^{1,2,3 \#}$, Lan-Qin Lin ${ }^{4 \#}$, Chao Chen ${ }^{1,2,3}$, Ting-Yu Chen ${ }^{1,2,3}$, Cheng-Xiong You ${ }^{1,2,3}$, \\ Rui-Qin Chen ${ }^{1,2,3}$, Cristian Deana ${ }^{5}$, Connor J. Wakefield ${ }^{6}$, Joseph B. Shrager ${ }^{7,8}$, Daniela Molena ${ }^{9}$, \\ Chi-Fu Jeffrey Yang $^{10}$, Ji-Hong Lin ${ }^{1,2,3}$, Shu-Chen Chen ${ }^{1,2,3}$
}

${ }^{1}$ Department of Thoracic Surgery, Fujian Medical University Union Hospital, Fuzhou, China; ${ }^{2}$ Key Laboratory of Ministry of Education for Gastrointestinal Cancer, Fujian Medical University, Fuzhou, China; ${ }^{3}$ Fujian Provincial Key Laboratory of Cardiothoracic Surgery, Fujian Medical University Union Hospital, Fuzhou, China; ${ }^{4}$ Department of Operation, Fujian Medical University Union Hospital, Fuzhou, China; ${ }^{5}$ Department of Anesthesia and Intensive Care, ASUFC-Academic Hospital of Udine, Udine, Italy; ${ }^{6}$ Department of Internal Medicine, Brooke Army Medical Center, Fort Sam Houston, TX, USA; ${ }^{7}$ Division of Thoracic Surgery, Department of Cardiothoracic Surgery, Stanford University School of Medicine, Stanford, CA, USA; ${ }^{8}$ Veterans Affairs Palo Alto Health Care System, Palo Alto, CA, USA; ${ }^{9}$ Thoracic Service, Department of Surgery, Memorial Sloan Kettering Cancer Center, New York, NY, USA; ${ }^{10}$ Department of Surgery, Division of Thoracic Surgery, Massachusetts General Hospital, Boston, MA, USA

Contributions: (I) Conception and design: JH Lin, SC Chen; (II) Administrative support: SC Chen; (III) Provision of study materials or patients: SJ Xu, LQ Lin, C Chen, TY Chen, CX You, RQ Chen; (IV) Collection and assembly of data: SJ Xu, LQ Lin, C Chen, TY Chen, CX You, RQ Chen; (V) Data analysis and interpretation: SJ Xu, LQ Lin; (VI) Manuscript writing: All authors; (VII) Final approval of manuscript: All authors.

"These authors contributed equally to this work and should be considered as co-first authors.

Correspondence to: Shu-Chen Chen, PhD; Ji-Hong Lin. Department of Thoracic Surgery, Fujian Medical University Union Hospital, No. 29 Xin Quan Road, Fuzhou 350001, China. Email: cscdoctor@163.com; ljh060@qq.com.

Background: The textbook outcome (TO) emerges as a novel prognostic factor in surgical oncology. The present study aimed to evaluate the effect of TO on the risk of death and recurrence in patients with esophageal squamous cell carcinoma (ESCC) after minimally invasive esophagectomy (MIE).

Methods: The study involved retrospective analysis of 528 patients with ESCC who were subjected to MIE from January 2011 to December 2017. TO included 8 parameters: complete resection; microscopically tumor-negative resection margins (R0); $\geq 15$ lymph nodes removed and examined; no serious postoperative complications; no postoperative intervention; no re-admission to the intensive care unit (ICU); hospital stay $\leq 21$ days; and no readmission $\leq 30$ days. The Cox and logistic regression model were used to analyze the prognostic factors of survival and risk factors for TO.

Results: Among the 528 patients with ESCC who were subjected to MIE, $53.2 \%$ reached TO. In the case of patients with locally advanced ESCC, 5-year overall survival (OS) was 51.1\% (41.2-61.2\%) for the TO group but 33.7\% (23.7-43.7\%) for the non-TO group (HR =0.644, 95\% CI: 0.449-0.924, P=0.015). Similarly, 5-year disease-free survival (DFS) was $47.6 \%(38.0-57.2 \%)$ for the TO group but 29.1\% (20.1$38.1 \%$ ) for the non-TO group ( $\mathrm{HR}=0.671,95 \% \mathrm{CI}: 0.479-0.940, \mathrm{P}=0.018$ ). In addition, 5-year recurrencefree survival (RFS) was $62.9 \%(53.7-72.1 \%)$ for the TO group but 39.8\% (29.4-50.2\%) for the non-TO group ( $\mathrm{HR}=0.606,95 \% \mathrm{CI}: 0.407-0.902, \mathrm{P}=0.012)$. Multivariate logistic regression analysis further showed that age, American Society of Anesthesiology (ASA) score, intraoperative blood loss, and smoking status acted as independent risk factors for TO. The results of the multivariate analysis assisted in the establishment of a nomogram for the prediction of TO occurrence. This nomogram exhibited satisfactory consistency and prediction ability [area under the receiving operator characteristic (AUROC) $=0.717$ ].

Conclusions: The present study showed that achieving of TO after MIE improves survival rate and reduce 
the recurrence rate in patients with locally advanced ESCC. The study further determined the independent factors associated with TO achievement and established a prediction model.

Keywords: Textbook outcome (TO); esophageal squamous cell carcinoma (ESCC); prognosis; nomogram

Submitted Nov 19, 2021. Accepted for publication Feb 18, 2022.

doi: 10.21037/atm-22-506

View this article at: https://dx.doi.org/10.21037/atm-22-506

\section{Introduction}

Esophageal cancer is one of the most common digestive tract cancers in the world, ranking seventh with regard to incidence and sixth with regard to cancer-related mortality (1). Esophageal squamous cell carcinoma (ESCC) is the most common type of esophageal cancer (2). Currently used treatment methods for ESCC include neoadjuvant radiotherapy and chemotherapy, open or minimally invasive esophagectomy (MIE), and postoperative adjuvant therapy (3-7). Although multimodal treatment is known to have a significant impact on the outcomes of patients with ESCC, there is still high rates of associated morbidity and mortality (8). Thus, there is a need to investigate which clinical factors are associated with improved overall survival (OS) and oncologic outcomes in patients with ESCC.

In recent years, certain studies have shown that postoperative complications of MIE, such as anastomotic leakage, greatly affect the prognosis in these patients (9-11). As a result, people gradually realize that in addition to the factors of the tumor itself, the perioperative medical quality also has a far-reaching impact on the long-term survival of patients (12). However, for patients with esophageal cancer, it is not enough to use a single discrete method to evaluate surgical effects on different individuals. In 2011, Busweiler et al. proposed a comprehensive method to measure the quality of upper gastrointestinal tumor surgery, which was termed the textbook outcome (TO). The TO includes 10 short-term indicators of surgical outcome from operation to discharge: radical resection according to the surgeon at the end of surgery, absence of any intraoperative complications, microscopically tumor-negative resection margins (R0), removal and examination of $\geq 15$ lymph nodes, absence of any serious postoperative complications, absence of postoperative intervention, no re-admission to the intensive care unit (ICU), a hospital stay $\leq 21$ days, no death postoperation( $\leq 30$ days), and no readmission after discharge (13). Many studies have previously shown that patients with gastric and esophageal cancer who reach TO represent ideal surgical clinical outcomes. Additionally, such patients also experience a significantly reduced future risk of death $(14,15)$.

In comparison to open esophagectomy (OE), MIE is considered to accelerate perioperative recovery in patients without affecting the long-term prognosis of the tumor (16-18). In the past few years, there has been significant development in MIE, leading to its wide use in clinics and its gradual replacement of traditional OE. Recent studies have suggested that MIE itself optimizes the quality of surgery and increases the possibility of achieving TO. When MIE was included as one of the parameters of TO, the combined TO resulted in significant improvement in the OS rate of patients with cancer $(19,20)$. Therefore, it is important to investigate the prognostic value of $\mathrm{TO}$ in patients with ESCC who are treated with MIE.

The present study aimed to evaluate the impact of achieving TO on the outcomes of patients with ESCC who underwent MIE. In addition, the factors related to TO were identified to facilitate the development of a model that could predict the occurrence of achieving TO. We present the following article in accordance with the STROBE reporting checklist (available at https://atm.amegroups.com/article/ view/10.21037/atm-22-506/rc).

\section{Methods}

This retrospective study was approved by the ethics committee of the Fujian Medical University Union Hospital (No. 2020KJT086), and all patients provided signed informed consent. The study was conducted in accordance with the Declaration of Helsinki Declaration (as revised in 2013).

\section{Study design and population}

This study retrospectively analyzed patients with ESCC who were treated at the Fujian Medical University Union 
Hospital from January 2011 to December 2017. The patient inclusion criteria were as follows: (I) pathologically confirmed ESCC (stages I-IVa); (II) underwent MIE; (III) no neoadjuvant radiotherapy or chemotherapy before operation; (IV) complete clinical information and followup data; and (V) no multiple primary cancers. The patient selection flow chart is illustrated in Figure S1. A total of 528 consecutive patients with ESCC were included for analysis. According to MIE outcome, the patients were divided into 2 groups, namely a TO group (281 patients, $53.2 \%$ ) and a non-TO group (247 patients, $46.8 \%$ ). The patients' clinical data were collected from these populations, including clinical and pathological parameters, surgical procedure, lymphadenectomy, postoperative adjuvant treatment, and follow-up information. The pathological diagnosis and staging were based on the TNM classification system of the $8^{\text {th }}$ edition of the American Joint Commission on Cancer (AJCC) (21).

All the patients included in this study were pathologically diagnosed with ESCC after undergoing MIE, including complete minimally invasive and mixed minimally invasive methods. The standard procedures were right thoracic esophagectomy, posterior mediastinal or retrosternal gastric tube reconstruction, cervical incision, or intrathoracic anastomosis.

The postoperative follow-up examinations included physical examination, blood biochemical examination, and imaging examination. In the first 2 years, the examinations were conducted every 3-6 months and thereafter every 6 months for 5 years. After 5 years, the examinations were performed once a year. When disease relapse was suspected, this was confirmed by computed tomography (CT) or endoscopy. The OS was defined as the time from the date of operation to death from any cause or the last followup. Disease-free survival (DFS) was defined as the time from the date of operation to death due to recurrence or other causes. Recurrence-free survival (RFS) was defined as the time from the date of operation to local or distant recurrence.

\section{Definitions}

The original Dutch Upper Gastrointestinal Cancer Audit (DUCA) definition of TO includes 10 features (13). Our TO included 8 parameters: complete resection according to the surgeons at the end of the surgery; microscopically tumor-negative resection margins (R0); $\geq 15$ lymph nodes removed and examined; no serious postoperative complications; no postoperative intervention; no readmission to the ICU after operation; hospital stay $\leq 21$ days; and no readmission $\leq 30$ days after discharge. When all the parameters were met, the requirements of TO were also met. According to the Clavien-Dindo classification, postoperative complications $\geq$ grade II indicated serious complications.

\section{Statistical analysis}

A $t$-test or a Mann-Whitney $\mathrm{U}$ test was performed to analyze the continuous variables. The classification variables of clinical features were tested using the Chi-square test or Fisher's exact test. According to MIE outcome, the patients were divided into a TO and a non-TO group. Sankey analysis was performed to visualize the proportion of different parameters of TO and the relationship between TO and recurrence and death. The independent influencing factors of OS, DFS, and RFS were determined by univariate and multivariate analyses of the Cox proportional hazard regression model. Kaplan-Meier was applied to the survival curve, while a logarithmic rank test was used to compare the survival rate between the 2 groups. A logistic regression analysis was applied to determine the factors influencing the possibility of TO occurrence, and the results of multiple factors were used to establish a nomogram so as to predict the realization of TO and to test the nomogram internally by Harrell's concordance index (C-index) and calibration curves.

IBM SPSS version 25.0 (IBM Corp., Armonk, NY, USA) and R version 3.5.1 (The R Foundation for Statistical Computing, Vienna, Austria) were used for the statistical analyses. $\mathrm{P}<0.05$ was considered statistically significant.

\section{Results}

\section{Clinical and pathological features}

The study involved a total of 528 patients with ESCC, with a median follow-up period of 53 months (range, 22-100 months). On univariate analysis, significant differences were recorded between the TO and non-TO groups in terms of American Society of Anesthesiology (ASA) score, T stage, intraoperative blood loss, and smoking status. However, no significant differences were recorded in operation year, age, sex, body mass index (BMI), tumor location, tumor grade, $\mathrm{N}$ stage, TNM stage, surgical procedure, lymphadenectomy, or postoperative adjuvant therapy $(\mathrm{P}>0.05$; Table 1$)$. 
Table 1 Characteristics of the participants in the TO and non-TO cohorts

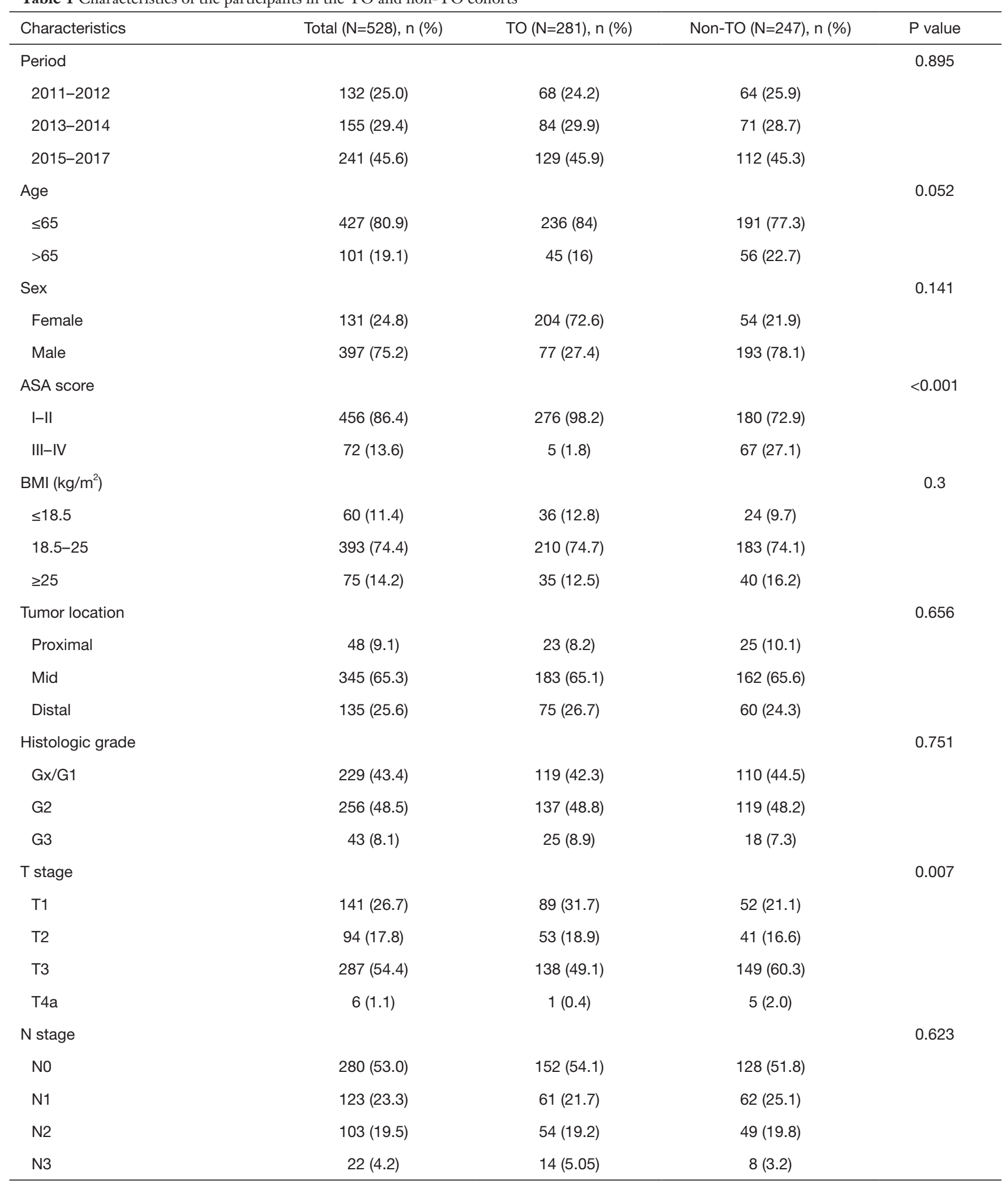

Table 1 (continued) 
Table 1 (continued)

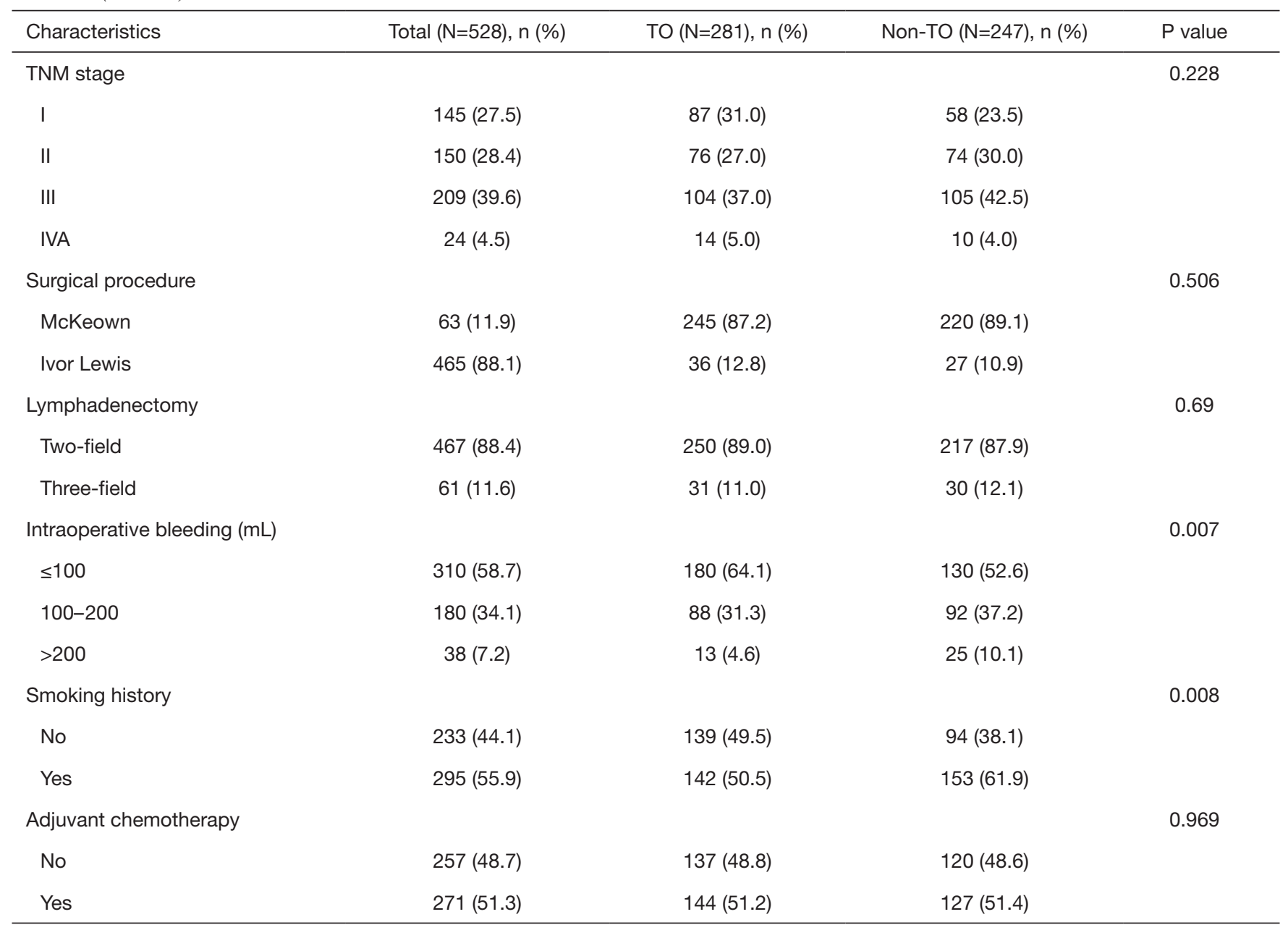

TO, textbook outcome; ASA, American Society of Anesthesiology; BMI, body mass index.

\section{TO after MIE of ESCC}

The scores for each quality index were calculated for the patients. In particular, $99.8 \%(527 / 528)$ of patients underwent radical resection according to the surgeon at the end of surgery, 99.4\% (525/528) received microscopically tumor-negative resection margins (R0), 94.8\% (501/528) received dissection $\geq 15$ lymph node, $98.7 \%$ (522/528) did not require admission to the ICU after the operation, $89.6 \%(473 / 528)$ did not require further intervention after the operation, $89.0 \%(470 / 528)$ had a postoperative hospital stay $\leq 21$ days, $56.1 \%$ (296/528) showed no serious complications, and $98.3 \%$ had no recorded readmission after the operation. The limiting factors for TO included lymph node dissection, postoperative intervention, postoperative hospital stay, and postoperative complications. Importantly, a total of 281 patients with ESCC achieved all
8 quality indicators, and $53.2 \%$ of the patients achieved TO (Figure 1).

\section{Survival analysis}

For patients with ESCC in the TO group, 5-year OS was $68.1 \%$ (61.8-74.4\%), 5-year DFS was 63.2\% (56.9-69.5\%), and 5-year RFS was $73.5 \%$ (67.6-79.4\%). However, for the non-TO group, 5-year OS, 5-year DFS, and 5-year RFS were $56.2 \%$ (49.1-63.3\%), 50.4\% (43.3-57.5\%), and $61.8 \%$ (54.9-68.7\%), respectively. Altogether, OS, DFS, and RFS were found to be significantly better in the TO group than those in the non-TO group $(\mathrm{P}<0.05$; Figure $2 A-2 C)$.

The association of TO status with oncologic outcomes were evaluated in patients with early (I-II) and locally advanced (III-IVA) ESCC were analyzed. No significant 


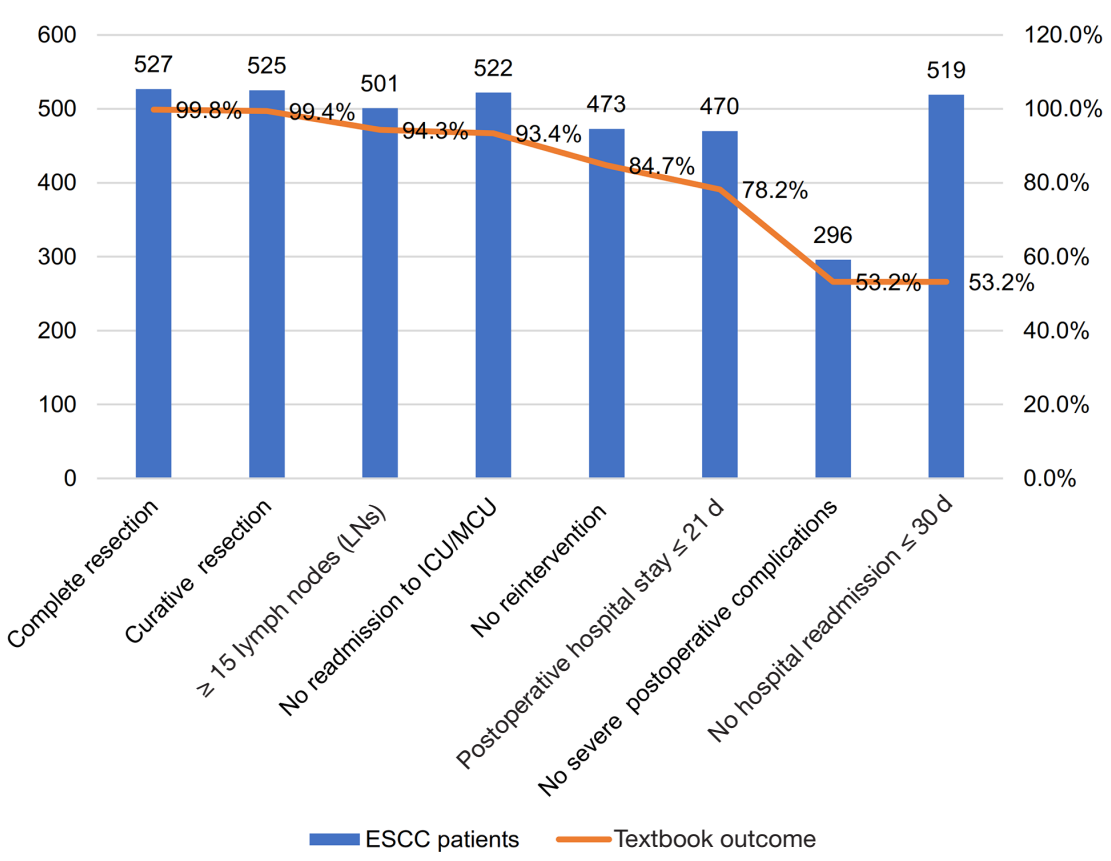

Figure 1 The cumulative incidence of TO in patients with ESCC after MIE and the number of patients with each surgical quality parameter. The bar indicates the number of patients who met each criterion; the broken line represents the cumulative percentage of patients who have achieved TO. TO, textbook outcome; ESCC, esophageal squamous cell carcinoma; MIE, minimally invasive esophagectomy; ICU, intensive care unit; $M C U$, medium care unit.

differences were recorded in OS, DFS, or RFS between the TO and non-TO groups in patients with early ESCC (Figure 3A-3C). However, in the case of patients with locally advanced ESCC, 5-year OS was 51.1\% (41.2-61.2\%) for the TO group but $33.7 \%$ (23.7-43.7\%) for the nonTO group (HR $=0.644,95 \%$ CI: 0.449-0.924, $\mathrm{P}=0.015$ ). Similarly, 5 -year DFS was $47.6 \%$ (38.0-57.2\%) for the TO group but $29.1 \%$ (20.1-38.1\%) for the non-TO group (HR $=0.671,95 \%$ CI: $0.479-0.940, \mathrm{P}=0.018)$. In addition, 5 -year RFS was $62.9 \%(53.7-72.1 \%$ ) for the TO group but $39.8 \%$ (29.4-50.2\%) for the non-TO group (HR $=0.606,95 \%$ CI: $0.407-0.902, \mathrm{P}=0.012$ ). Patients with locally advanced ESCC who reached TO conditions exhibited a reduction in risk of death by $35.5 \%$ and a reduction in risk of recurrence by $39.4 \%$ (Figure $3 D-3 F$ ).

The dynamic display function of the Sankey plot was used to show the relationship between the 8 quality indices that affect $\mathrm{TO}$ and death and recurrence in patients with locally advanced ESCC. As shown in Figure 4A, the majority of patients given the status of "Alive" belonged to the TO group $(58.9 \%)$ who met all 8 indicators, while only $41.1 \%$ of the "Alive" patients belonged to the non-
TO group. Similarly, the "no recurrence" status was mainly given to patients belonging to the TO group (58.3\%), while the non-TO group accounted for only $41.7 \%$ of "no recurrence" patients (Figure 4B).

\section{TO as a protective factor in patients with ESCC}

Univariate Cox regression analysis was used to further evaluate the clinicopathological factors that affect the prognosis of patients with ESCC. The analysis showed that age, ASA score, TNM stage, intraoperative blood loss, and TO were significant prognostic factors for OS. Multivariate Cox analysis showed that age ( $>65 v s . \leq 65$ years: $\mathrm{HR}=1.542$, 95\% CI: 1.099-2.163, $\mathrm{P}=0.012$ ), TNM stage (IVA vs. I: $\mathrm{HR}=13.733,95 \%$ CI: 6.812-27.685, $\mathrm{P}<0.001$; III vs. I: $\mathrm{HR}=6.094,95 \%$ CI: 3.483-10.662, $\mathrm{P}<0.001$; II vs. I: HR $=3.022,95 \%$ CI: $1.655-5.518, \mathrm{P}<0.001)$, and intraoperative blood loss $(\geq 200$ vs. $\leq 100 \mathrm{~mL}: \mathrm{HR}=1.925,95 \%$ CI: 1.179 3.143, $\mathrm{P}=0.009 ; 100-200$ vs. $\leq 100 \mathrm{~mL}$ : HR $=1.230,95 \% \mathrm{CI}$ : 0.896-1.688, $\mathrm{P}=0.200$ ) acted as independent risk factors for OS, while TO (HR $=0.730,95 \%$ CI: $0.541-0.984, \mathrm{P}=0.039$ ) was an independent protective factor for OS (Table 2). 

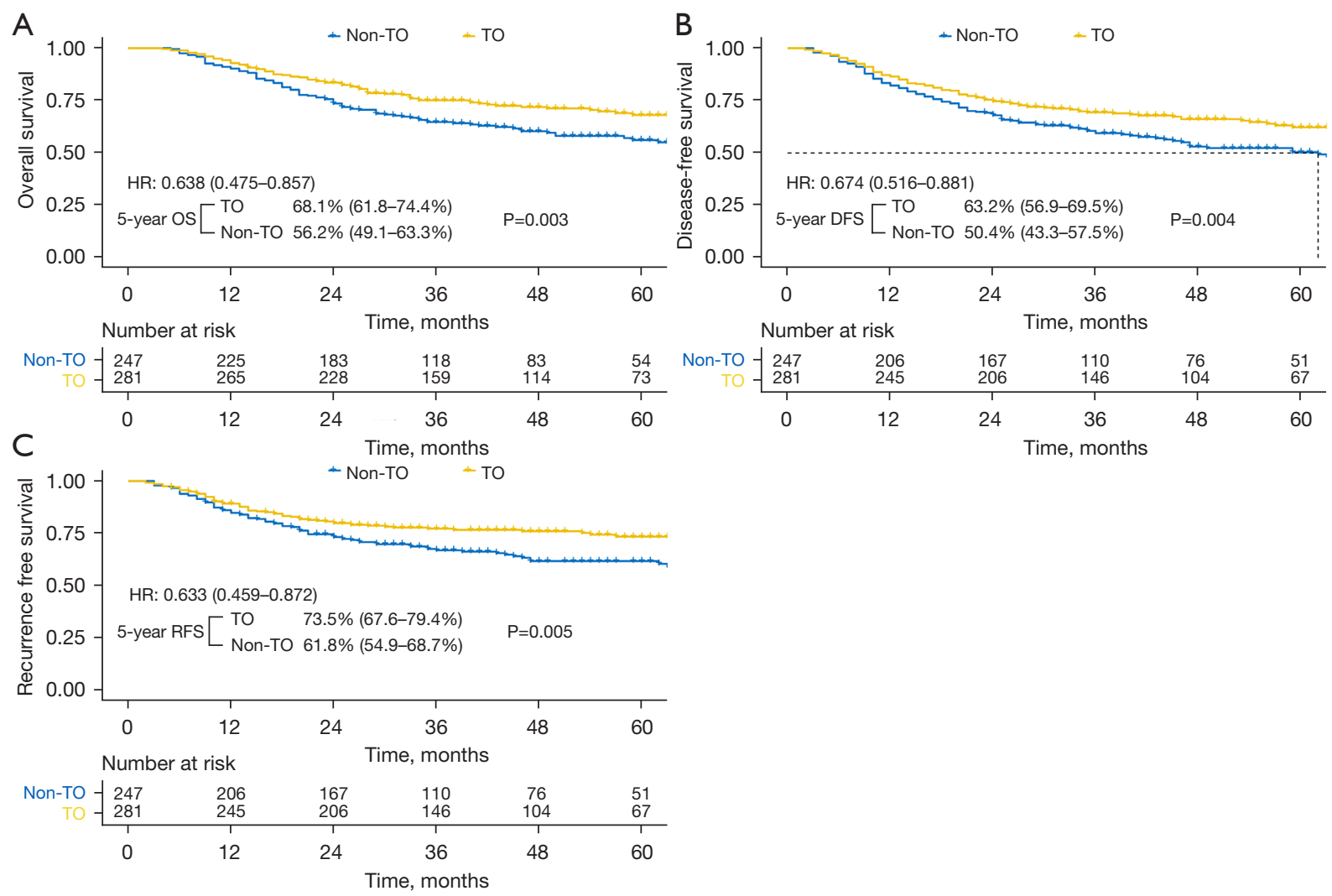

Figure 2 Kaplan-Meier survival curves of OS, DFS, and RFS for patients who underwent MIE for ESCC. TO, textbook outcome; OS, overall survival; DFS, disease-free survival; RFS, recurrence-free survival; MIE, minimally invasive esophagectomy; ESCC, esophageal squamous cell carcinoma.

Similarly, TO acted as an independent protective factor for both DFS and RFS (Tables S1,S2).

\section{TO-associated factors and development of a nomogram for predicting TO}

Logistic univariate analysis was used to analyze the factors that affect TO before and during operation. The results of the analysis showed that ASA score, intraoperative blood loss, and smoking status were significantly related to the realization of TO. Further, multivariate analysis showed that age ( $>65$ vs. $\leq 65$ years: OR $=0.478,95 \%$ CI: $0.293-$ $0.780, \mathrm{P}=0.003$ ), ASA score (III-IV vs. I-II: $\mathrm{OR}=0.042$, 95\% CI: $0.016-0.108, \mathrm{P}=0.042$ ), intraoperative blood loss ( $\geq 200$ vs. $\leq 100 \mathrm{~mL}:$ OR $=0.334,95 \%$ CI: $0.157-0.713$, $\mathrm{P}=0.005 ; 100-200$ vs. $\leq 100 \mathrm{~mL}: \mathrm{OR}=0.644,95 \% \mathrm{CI}$ : $0.430-0.965, \mathrm{P}=0.033$ ), and smoking status (current/former vs. never: $\mathrm{OR}=0.522,95 \% \mathrm{CI}$ : $0.350-0.779, \mathrm{P}=0.001)$ acted as independent risk factors for TO (Table 3).
The results of the logistic multivariate analysis were used to construct a predictive model based on age, ASA score, intraoperative blood loss, and smoking status (Figure $5 \mathrm{~A}$ ). The nomogram exhibited good accuracy in estimating the possibility of achieving TO (area under the receiving operator characteristic, AUROC: $0.717,95 \%$ CI: $0.673-$ 0.761 ; Figure $5 B$ ). The calibration curve graphically showed that a good consistency existed between the risk estimation based on the nomogram and actual clinical TO (Figure 5C). The Hosmer-Lemeshow test showed that the $\mathrm{P}$ value was 0.988 , which indicated that the nomogram had a good predictive ability.

In this study, a total of $53.2 \%$ of the patients reached TO. According to the nomogram prediction for the possibility of achieving TO, the patients were divided into 2 groups, namely a low probability group for achieving TO (nomogram score $<135$ ) and a high probability group for achieving TO (nomogram score $\geq 135$ ). The odds for achieving TO in the 2 groups were recorded to be $11.9 \%$ 

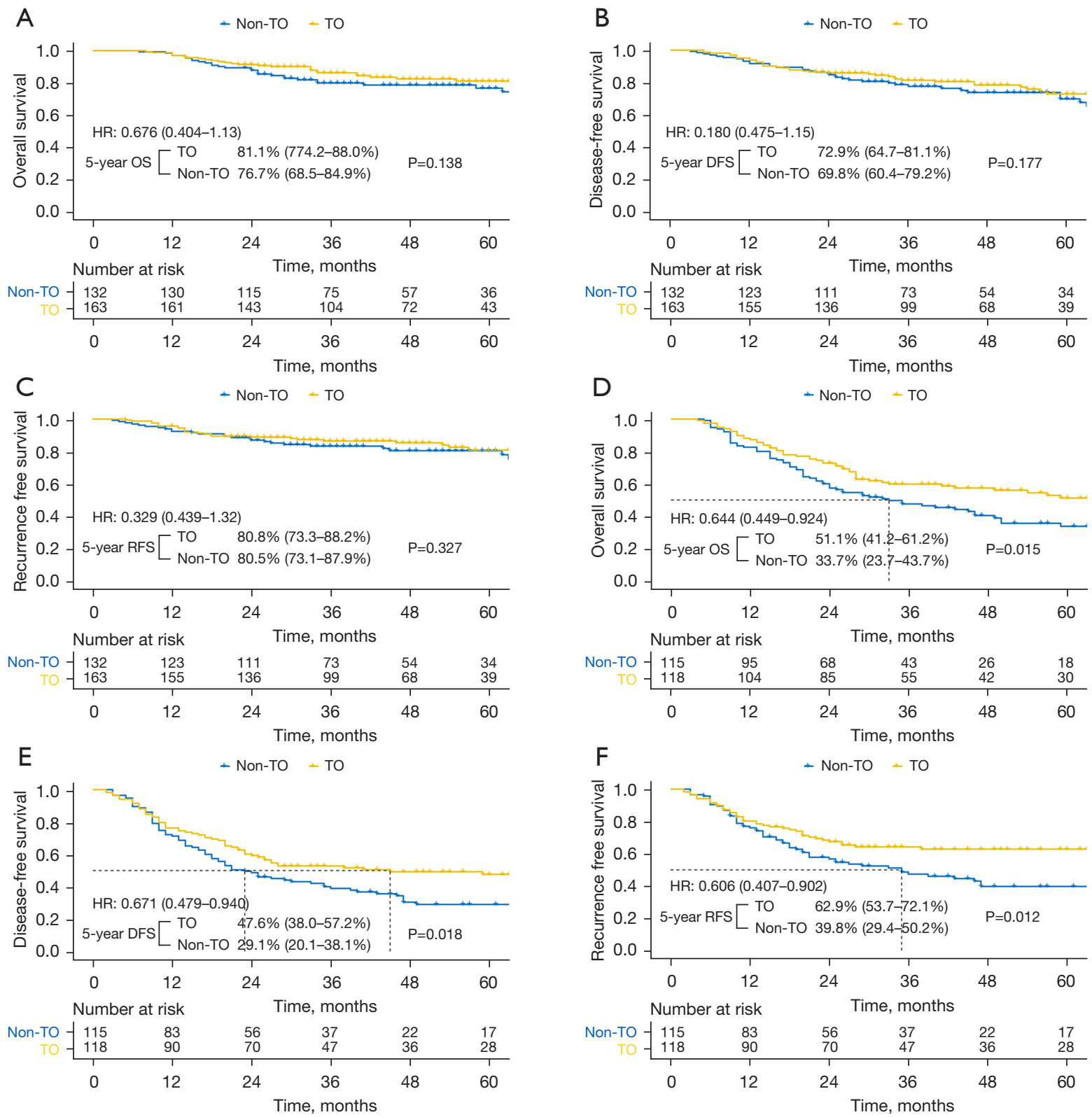

Figure 3 Kaplan-Meier survival curves stratified by early stages (A-C) and locally advanced stages (D-F). TO, textbook outcome; OS, overall survival; DFS, disease-free survival; RFS, recurrence-free survival.

$(63 / 528)$ and $41.3 \%(218 / 528)$, respectively (Figure S2).

\section{Discussion}

Various studies have shown that perioperative complications of esophageal cancer surgery affect the short- and longterm outcomes of patients. This suggests that the quality of the esophagectomy surgery acts as an important predictor of oncology outcome $(9,10)$. TO was proposed as a comprehensive index to evaluate the quality and effect of the surgery on patients with esophageal cancer and colon cancer (22). Previous studies have used TO to compare differences in medical quality between different hospitals $(13,23)$. Some recent studies have reported that the realization of TO is related to the prognosis of esophageal cancer, and that TO-compliant patients exhibit an increased 

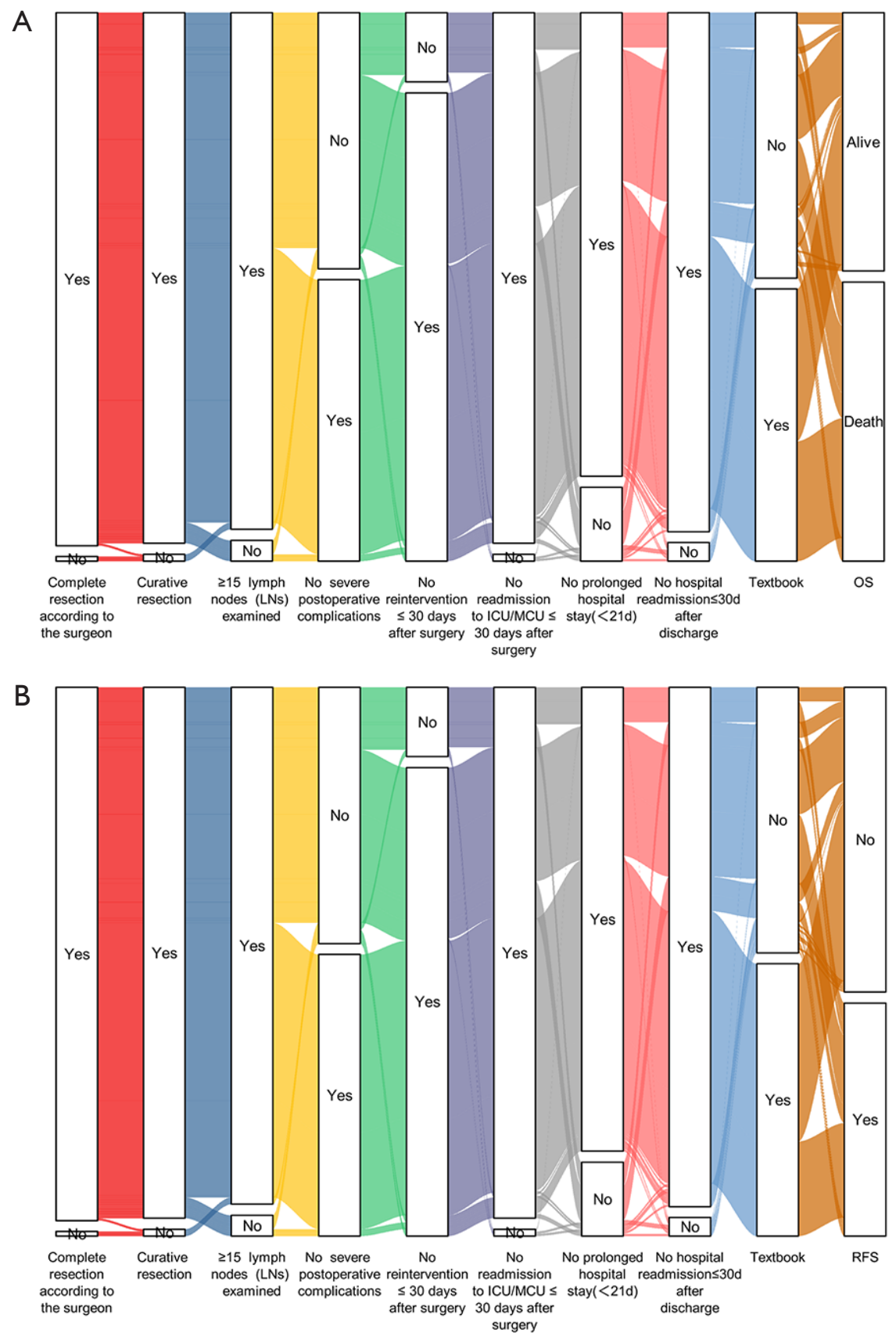

Figure 4 The Sankey graph dynamically illustrates the flow relationship between TO and the 8 different indicators and that between TO and the final prediction results. (A) TO flows to the survival outcome; (B) TO flows to the recurrence outcome. TO, textbook outcome; OS, overall survival; RFS, recurrence-free survival; ICU, Intensive care unit; MCU, medium care unit.

OS rate and reduced risk of death $(19,20)$. However, in the era of minimally invasive treatment, the prognosis of TO in patients with ESCC who undergo MIE remains unclear. This is the first report that investigated the clinical significance of achieving TO in ESCC patients who underwent MIE.
Moreover, to facilitate the clinical application of TO, a nomogram was established to predict achievement of TO, which could provide clinicians with decision-making advice on optimizing the quality of surgery.

The definition of TO generally varies according to the 
Table 2 Univariate and multivariate Cox analysis of clinicopathological factors for OS

\begin{tabular}{|c|c|c|c|c|c|c|}
\hline Factors & \multicolumn{3}{|c|}{ Univariate analysis } & \multicolumn{3}{|c|}{ Multivariate analysis } \\
\hline \multicolumn{7}{|l|}{ Period } \\
\hline 2011-2012 & Ref. & & & & & \\
\hline 2013-2014 & 0.871 & $0.602-1.262$ & 0.466 & & & \\
\hline \multicolumn{7}{|l|}{ Age } \\
\hline$\leq 65$ & Ref. & & & Ref. & & \\
\hline$>65$ & 1.620 & $1.159-2.267$ & 0.005 & 1.542 & $1.099-2.163$ & 0.012 \\
\hline \multicolumn{7}{|l|}{ Sex } \\
\hline \multicolumn{7}{|l|}{ ASA score } \\
\hline I-II & Ref. & & & & & \\
\hline III-IV & 0.023 & $1.066-2.342$ & 0.023 & & & \\
\hline \multicolumn{7}{|l|}{ BMI $\left(\mathrm{kg} / \mathrm{m}^{2}\right)$} \\
\hline$\leq 18.5$ & Ref. & & & & & \\
\hline $18.5-25$ & 1.183 & $0.723-1.936$ & 0.503 & & & \\
\hline$\geq 25$ & 1.317 & $0.728-2.381$ & 0.362 & & & \\
\hline \multicolumn{7}{|c|}{ Tumor location } \\
\hline \multicolumn{7}{|c|}{ Histologic grade } \\
\hline $\mathrm{Gx} / \mathrm{G} 1$ & Ref. & & & & & \\
\hline G2 & 0.394 & $0.840-1.560$ & 0.394 & & & \\
\hline G3 & 1.292 & $0.762-2.191$ & 0.342 & & & \\
\hline \multicolumn{7}{|l|}{ TNM stage } \\
\hline I & Ref. & & & Ref. & & \\
\hline II & 3.256 & $1.784-5.941$ & $<0.001$ & 3.022 & $1.655-5.518$ & $<0.001$ \\
\hline III & 6.418 & $3.671-11.220$ & $<0.001$ & 6.094 & $3.483-10.662$ & $<0.001$ \\
\hline IVA & 13.767 & $6.838-27.717$ & $<0.001$ & 13.733 & $6.812-27.685$ & $<0.001$ \\
\hline \multicolumn{7}{|c|}{ Surgical procedure } \\
\hline McKeown & Ref. & & & & & \\
\hline Ivor Lewis & 0.755 & $0.469-1.216$ & 0.249 & & & \\
\hline
\end{tabular}

Table 2 (continued) 
Table 2 (continued)

\begin{tabular}{|c|c|c|c|c|c|c|}
\hline Factors & \multicolumn{3}{|c|}{ Univariate analysis } & \multicolumn{3}{|c|}{ Multivariate analysis } \\
\hline \multicolumn{7}{|c|}{ Lymphadenectomy } \\
\hline Two-field & Ref. & & & & & \\
\hline Three-field & 0.921 & $0.588-1.442$ & 0.718 & & & \\
\hline$\leq 100$ & Ref. & & & Ref. & & \\
\hline $100-200$ & 1.262 & $0.921-1.728$ & 0.147 & 1.230 & $0.896-1.688$ & 0.200 \\
\hline$\geq 200$ & 2.005 & $1.234-3.255$ & 0.005 & 1.925 & $1.179-3.143$ & 0.009 \\
\hline \multicolumn{7}{|l|}{ Smoking status } \\
\hline \multicolumn{7}{|c|}{ Adjuvant chemotherapy } \\
\hline No & Ref. & & & & & \\
\hline Yes & 1.209 & $0.900-1.625$ & 0.207 & & & \\
\hline \multicolumn{7}{|l|}{ TO } \\
\hline No & Ref. & & & Ref. & & \\
\hline Yes & 0.638 & $0.475-0.857$ & 0.003 & 0.730 & $0.541-0.984$ & 0.039 \\
\hline
\end{tabular}

OS, overall survival; ASA, American Society of Anesthesiology; BMI, body mass index; TO, textbook outcome; HR, hazard ratio; Cl, confidence interval.

Table 3 Univariate and multivariate analysis of possible predictors for achievement of TO after MIE

\begin{tabular}{|c|c|c|c|c|c|c|}
\hline Factors & \multicolumn{3}{|c|}{ Univariate analysis } & \multicolumn{3}{|c|}{ Multivariate analysis } \\
\hline \multicolumn{7}{|l|}{ Period } \\
\hline 2011-2012 & Ref. & & & & & \\
\hline 2013-2014 & 1.114 & $0.699-1.773$ & 0.651 & & & \\
\hline \multicolumn{7}{|l|}{ Age } \\
\hline$\leq 65$ & Ref. & & & Ref. & & \\
\hline$>65$ & 0.650 & $0.420-1.006$ & 0.053 & 0.478 & $0.293-0.780$ & 0.003 \\
\hline \multicolumn{7}{|l|}{ Sex } \\
\hline
\end{tabular}

Table 3 (continued) 
Table 3 (continued)

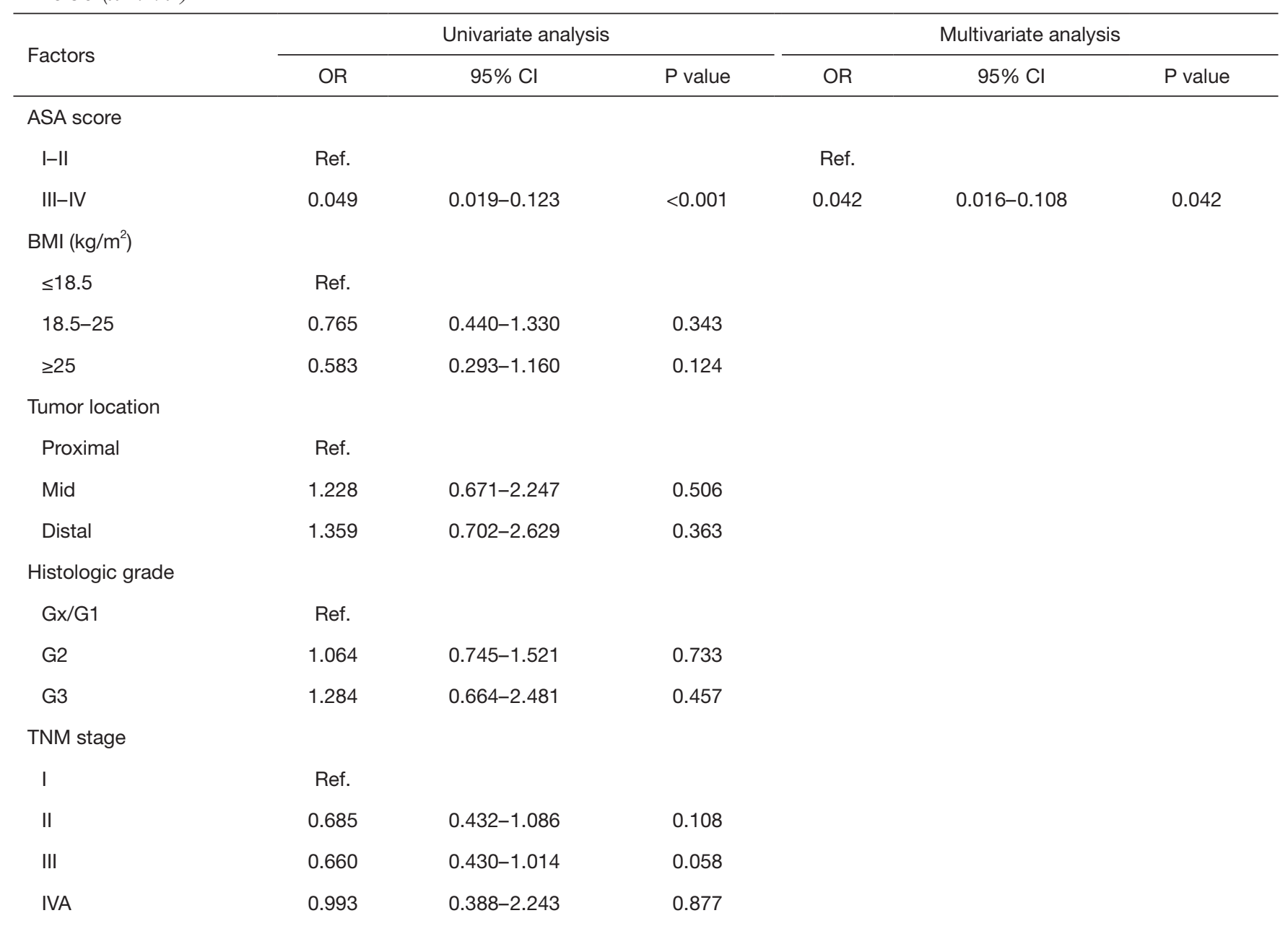

Surgical procedure

McKeown Ref.

Ivor Lewis $\quad 1.197$

$0.704-2.036$

0.506

Lymphadenectomy

Two-field

Three-field

Blood loss (mL)

$\begin{array}{lc}\leq 100 & \text { Ref. } \\ 100-200 & 0.691 \\ \geq 200 & 0.376\end{array}$

Smoking status

Never

Ref.

Ref.

0.897

0.526-1.530

0.690

Ref.

0.691

0.478-0.999

0.185-0.762

0.050

0.007

Ref.

0.644

0.430-0.965

0.033

0.334

$0.157-0.713$

0.005

Ref.

Current/former

0.628

0.443-0.888

TO, textbook outcome; MIE, minimally invasive esophagectomy; ASA, American Society of Anesthesiology; BMI, body mass index; OR, odd ratio; $\mathrm{Cl}$, confidence interval. 

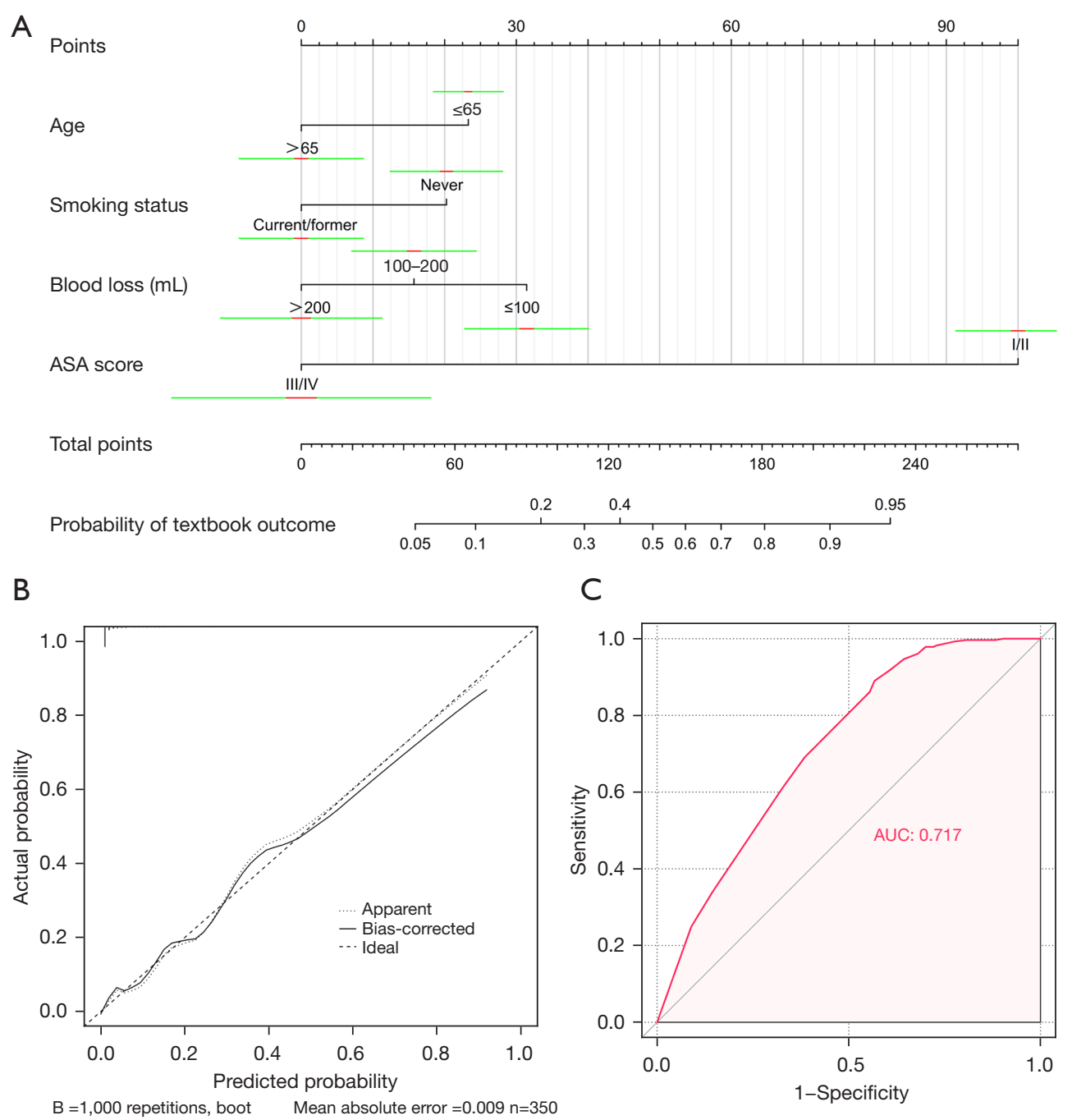

Figure 5 Nomogram and performance evaluation. (A) Nomogram for predicting TO. (B) Calibration curve of the nomogram. (C) ROC curve of the nomogram. TO, textbook outcome; ASA, American society of Anesthesiology; ROC, receiver operating characteristic.

type, mechanism, and parameters of the tumor (24-26). The definition of TO considered in this study was based on 8 short-term outcome indicators of ESCC patients after MIE. Since there were no clearly defined intraoperative complications in previous studies, and patient death within 30 days after surgery didn't affect the TO for long-term prognosis prediction in patients with ESCC. So, in this study, we did not include the parameters of intraoperative complications and postoperative death in TO. The results of the study showed that the rate of patients with ESCC who reached TO after MIE was $53.2 \%$. However, previous studies have reported that the incidence of TO in esophageal cancer is less than $40 \%(14,19,23)$. This difference might be due to the inclusion of patients who underwent both MIE and OE in previous studies. In comparison to OE, MIE is associated with significant advantages in the perioperative period, such as reduced postoperative complications and improved quality of operation $(3,16)$.

The present study found that achieving a TO was significantly associated with improved OS, DFS, and RFS in patients with ESCC. The multivariate analysis showed that TO acted as an independent prognostic protective factor for patients with ESCC. In a subgroup analysis of patients with earl-stage ESCC, TO was not significantly associated with early ESCC who fulfilled the requirements of TO. 
In contrast, the patients with locally advanced ESCC who achieved TO exhibited a reduction in the risk of death by $35.5 \%$ and risk of recurrence by $39.4 \%$. The dynamic display function, assessed using a Sankey plot, also showed that there was a significant difference in the "alive" and "no recurrence" status between the TO group and the nonTO group in patients with locally advanced ESCC (alive: $58.9 \%$ vs. $41.1 \%$; no recurrence: $58.3 \%$ vs. $41.7 \%$ ). These results suggested that successful surgery and optimized postoperative management were associated with long-term outcomes in patients with locally advanced ESCC.

Non-TO status may be a poor prognostic factor in the case of patients with locally advanced ESCC, primarily owing to the quality of surgery and postoperative complications. In this study, lymph node dissection number, postoperative intervention, postoperative hospital stay, and postoperative complications were the main factors that limited TO. Serious postoperative complications were associated with postoperative re-intervention and prolonged postoperative hospital stay. Therefore, the number of lymph nodes dissected and the occurrence of severe postoperative complications were the 2 main independent factors that resulted in the observed decrease in the incidence of TO. Several studies have previously established the prognostic value of at least 15 lymph nodes resected in patients with esophageal cancer (27-29). Severe postoperative complications are known to increase the level of inflammation in the blood of patients with cancer, and the changes in the immune system may influence the process of cancer recurrence $(10,30,31)$.

In this study, factors that contributed to the achievement of TO included age $\leq 65$ years, ASA score of I-II, intraoperative blood loss of $\leq 100 \mathrm{~mL}$, and no previous history of smoking. Previous studies have established that higher ASA grades and older age are positively correlated with the probability of postoperative esophageal complications (32,33). Less intraoperative blood loss also directly affects postoperative recovery in patients, thereby increasing the incidence of TO. Importantly, the absence of a previous history of smoking has been shown to reduce the incidence of postoperative lung disease. Smoking is also considered to be a risk factor for morbidity after esophagectomy, especially in cases involving pulmonary complications $(34,35)$. In clinical practice, ECSS patients with these high-risk factors should be identified, and a more comprehensive treatment plan should be developed for such patients. To facilitate clinical evaluation, a nomogram was established that could individually predict the possibility of TO occurrence in patients with ESCC. According to the predicted scores of the nomogram, the entire patient population was divided into 2 groups, a low probability group and a high probability group, was calculated to be $11.9 \%$ and $41.3 \%$, respectively. Therefore, when predicting the incidence of postoperative low probability TO in patients with locally advanced ESCC, the importance of postoperative high-quality nursing should be emphasized.

The present study has several limitations. The study included patients belonging to single-center institutions, and so the possibility of selection bias could not be ruled out. Although the present prognostic study included detailed information about death and recurrence, the mechanism responsible for the effect of non-TO status on death and recurrence in patients with ESCC was not clear. This might be related to the number of lymph node dissections and/or inflammatory factors, which could not be confirmed in the present study. Lastly, only internal verification of the nomogram was carried out. Thus, there is a need to conduct external verification using another independent patient population in the future.

Overall, our investigation of TO and its impact on the outcomes of patients with ESCC who undergo MIE demonstrated that TO is associated with improved OS, DFS, and RFS in those with locally advanced ESCC. Several perioperative risk factors were identified, including age, ASA score, intraoperative blood loss, and smoking status, which were found to be significantly associated with achieving TO. Knowledge of this can directly help surgeons in the preoperative period to plan accordingly to mitigate these risk factors in an effort to achieve TO and to promote improved long-term outcomes in patients with ESCC who undergo MIE.

\section{Acknowledgments}

The authors appreciate the academic support from the AME Thoracic Surgery Collaborative Group.

Funding: This study was supported by grants from the Program for the Natural Science Foundation in Fujian Province (No. 2020J011004), Medical Innovation Project in Fujian Province (No. 2020CXA028), and the Cohort Study of the School of Public Health, Fujian Medical University (No. 2021HX003).

\section{Footnote}

Reporting Checklist: The authors have completed the 
STROBE reporting checklist. Available at https://atm. amegroups.com/article/view/10.21037/atm-22-506/rc

Data Sharing Statement: Available at https://atm.amegroups. com/article/view/10.21037/atm-22-506/dss

Conflicts of Interest: All authors have completed the ICMJE uniform disclosure form (available at https:// atm.amegroups.com/article/view/10.21037/atm-22-506/ coif). DM is a consultant for Johnson \& Johnson, Boston Scientific, Merck and in steering committee of AstraZeneca. The other authors have no conflicts of interest to declare.

Ethical Statement: The authors are accountable for all aspects of the work in ensuring that questions related to the accuracy or integrity of any part of the work are appropriately investigated and resolved. This retrospective study was approved by the ethics committee of the Fujian Medical University Union Hospital (No. 2020KJT086), and all patients provided signed informed consent. The study was conducted in accordance with the Declaration of Helsinki Declaration (as revised in 2013).

Open Access Statement: This is an Open Access article distributed in accordance with the Creative Commons Attribution-NonCommercial-NoDerivs 4.0 International License (CC BY-NC-ND 4.0), which permits the noncommercial replication and distribution of the article with the strict proviso that no changes or edits are made and the original work is properly cited (including links to both the formal publication through the relevant DOI and the license). See: https://creativecommons.org/licenses/by-nc-nd/4.0/.

\section{References}

1. Bray F, Ferlay J, Soerjomataram I, et al. Global cancer statistics 2018: GLOBOCAN estimates of incidence and mortality worldwide for 36 cancers in 185 countries. CA Cancer J Clin 2018;68:394-424.

2. Arnold M, Soerjomataram I, Ferlay J, et al. Global incidence of oesophageal cancer by histological subtype in 2012. Gut 2015;64:381-7.

3. Yang W, Liu F, Xu R, et al. Is adjuvant therapy a better option for esophageal squamous cell carcinoma patients treated with esophagectomy? A prognosis prediction model based on multicenter real-world data. Ann Surg 2021. [Epub ahead of print]. doi: 10.1097/ SLA.0000000000004958.
4. Ajani JA, D'Amico TA, Bentrem DJ, et al. Esophageal and Esophagogastric Junction Cancers, Version 2.2019, NCCN Clinical Practice Guidelines in Oncology. J Natl Compr Canc Netw 2019;17:855-83.

5. Palazzo F, Rosato EL, Chaudhary A, et al. Minimally invasive esophagectomy provides significant survival advantage compared with open or hybrid esophagectomy for patients with cancers of the esophagus and gastroesophageal junction. J Am Coll Surg 2015;220:672-9.

6. Yang H, Liu H, Chen Y, et al. Long-term Efficacy of Neoadjuvant Chemoradiotherapy Plus Surgery for the Treatment of Locally Advanced Esophageal Squamous Cell Carcinoma: The NEOCRTEC5010 Randomized Clinical Trial. JAMA Surg 2021;156:721-9.

7. Wang H, Tang H, Fang Y, et al. Morbidity and Mortality of Patients Who Underwent Minimally Invasive Esophagectomy After Neoadjuvant Chemoradiotherapy vs Neoadjuvant Chemotherapy for Locally Advanced Esophageal Squamous Cell Carcinoma: A Randomized Clinical Trial. JAMA Surg 2021;156:444-51.

8. Hou S, Pan Z, Hao X, et al. Recent Progress in the Neoadjuvant Treatment Strategy for Locally Advanced Esophageal Cancer. Cancers (Basel) 2021;13:5162.

9. Fransen LFC, Berkelmans GHK, Asti E, et al. The Effect of Postoperative Complications After Minimally Invasive Esophagectomy on Long-term Survival: An International Multicenter Cohort Study. Ann Surg 2021;274:e1129-37.

10. Saunders JH, Yanni F, Dorrington MS, et al. Impact of postoperative complications on disease recurrence and long-term survival following oesophagogastric cancer resection. Br J Surg 2020;107:103-12.

11. Deana C, Vetrugno L, Stefani F, et al. Postoperative complications after minimally invasive esophagectomy in the prone position: any anesthesia-related factor? Tumori 2021;107:525-35.

12. Hallet J, Jerath A, Turgeon AF, et al. Association Between Anesthesiologist Volume and Short-term Outcomes in Complex Gastrointestinal Cancer Surgery. JAMA Surg 2021;156:479-87.

13. Busweiler LA, Schouwenburg MG, van Berge Henegouwen MI, et al. Textbook outcome as a composite measure in oesophagogastric cancer surgery. Br J Surg 2017;104:742-50.

14. Kulshrestha S, Bunn C, Patel PM, et al. Textbook oncologic outcome is associated with increased overall survival after esophagectomy. Surgery 2020;168:953-61.

15. van der Werf LR, Wijnhoven BPL, Fransen LFC, et al. A National Cohort Study Evaluating the Association 
Between Short-term Outcomes and Long-term Survival After Esophageal and Gastric Cancer Surgery. Ann Surg 2019;270:868-76.

16. Zheng Y, Li Y, Liu X, et al. Minimally Invasive Versus Open McKeown for Patients with Esophageal Cancer: A Retrospective Study. Ann Surg Oncol 2021;28:6329-36.

17. Gottlieb-Vedi E, Kauppila JH, Mattsson F, et al. Longterm survival in esophageal cancer after minimally invasive esophagectomy compared to open esophagectomy. Ann Surg 2021. [Epub ahead of print]. doi: 10.1097/ SLA.0000000000004645.

18. Kalff MC, Fransen LFC, de Groot EM, et al. LongTerm Survival After Minimally Invasive Versus Open Esophagectomy for Esophageal Cancer: A Nationwide Propensity-Score Matched Analysis. Ann Surg 2020. [Epub ahead of print]. doi: 10.1097/SLA.0000000000004708.

19. Kalff MC, Vesseur I, Eshuis WJ, et al. The Association of Textbook Outcome and Long-Term Survival After Esophagectomy for Esophageal Cancer. Ann Thorac Surg 2021;112:1134-41.

20. Sędłak K, Rawicz-Pruszyński K, Mlak R, et al. Union is strength: Textbook outcome with perioperative chemotherapy compliance decreases the risk of death in advanced gastric cancer patients. Eur J Surg Oncol 2021. [Epub ahead of print].

21. Rice TW, Ishwaran H, Ferguson MK, et al. Cancer of the Esophagus and Esophagogastric Junction: An Eighth Edition Staging Primer. J Thorac Oncol 2017;12:36-42.

22. Busweiler LA, Wijnhoven BP, van Berge Henegouwen MI, et al. Early outcomes from the Dutch Upper Gastrointestinal Cancer Audit. Br J Surg 2016;103:1855-63.

23. van der Kaaij RT, de Rooij MV, van Coevorden F, et al. Using textbook outcome as a measure of quality of care in oesophagogastric cancer surgery. Br J Surg 2018;105:561-9.

24. Chen Q, Ning Z, Liu Z, et al. Textbook Outcome as a measure of surgical quality assessment and prognosis in gastric neuroendocrine carcinoma: A large multicenter sample analysis. Chin J Cancer Res 2021;33:433-46.

25. Kulshrestha S, Vigneswaran WT, Pawlik TM, et al. Assessment of Textbook Outcome After Surgery for Stage I/II Non-small Cell Lung Cancer. Semin Thorac Cardiovasc Surg 2021. [Epub ahead of print]. doi: 10.1053/ j.semtcvs.2021.08.009.

26. Warps AK, Detering R, Tollenaar RAEM, et al. Textbook outcome after rectal cancer surgery as a composite measure for quality of care: A population-based study. Eur J Surg
Oncol 2021;47:2821-9.

27. Hylton DA, Turner S, Kidane B, et al. The Canada Lymph Node Score for prediction of malignancy in mediastinal lymph nodes during endobronchial ultrasound. J Thorac Cardiovasc Surg 2020;159:2499-2507.e3.

28. Kong SH, Lee HJ, Ahn HS, et al. Stage migration effect on survival in gastric cancer surgery with extended lymphadenectomy: the reappraisal of positive lymph node ratio as a proper N-staging. Ann Surg 2012;255:50-8.

29. Lin CS, Cheng CT, Liu CY, et al. Radical Lymph Node Dissection in Primary Esophagectomy for Esophageal Squamous Cell Carcinoma. Ann Thorac Surg 2015;100:278-86.

30. Yoo HM, Lee HH, Shim JH, et al. Negative impact of leakage on survival of patients undergoing curative resection for advanced gastric cancer. J Surg Oncol 2011;104:734-40.

31. Sierzega M, Kolodziejczyk P, Kulig J, et al. Impact of anastomotic leakage on long-term survival after total gastrectomy for carcinoma of the stomach. Br J Surg 2010;97:1035-42.

32. Janssen HJB, Gantxegi A, Fransen LFC, et al. Risk Factors for Failure of Direct Oral Feeding Following a Totally Minimally Invasive Esophagectomy. Nutrients 2021;13:3616.

33. Tang Z, Lu M, Qu C, et al. Enhanced Recovery After Surgery Improves Short-term Outcomes in Patients Undergoing Esophagectomy. Ann Thorac Surg 2021. [Epub ahead of print]. doi: 10.1016/ j.athoracsur.2021.08.073.

34. Ferguson MK, Celauro AD, Prachand V. Prediction of major pulmonary complications after esophagectomy. Ann Thorac Surg 2011;91:1494-1500; discussion 1500-1.

35. Kamarajah SK, Madhavan A, Chmelo J, et al. Impact of Smoking Status on Perioperative Morbidity, Mortality, and Long-Term Survival Following Transthoracic Esophagectomy for Esophageal Cancer. Ann Surg Oncol 2021;28:4905-15.

Cite this article as: $\mathrm{Xu} \mathrm{SJ}$, Lin LQ, Chen C, Chen TY, You CX, Chen RQ, Deana C, Wakefield CJ, Shrager JB, Molena D, Yang CJ, Lin JH, Chen SC. Textbook outcome after minimally invasive esophagectomy is an important prognostic indicator for predicting long-term oncological outcomes with locally advanced esophageal squamous cell carcinoma. Ann Transl Med 2022;10(4):161. doi: 10.21037/atm-22-506 


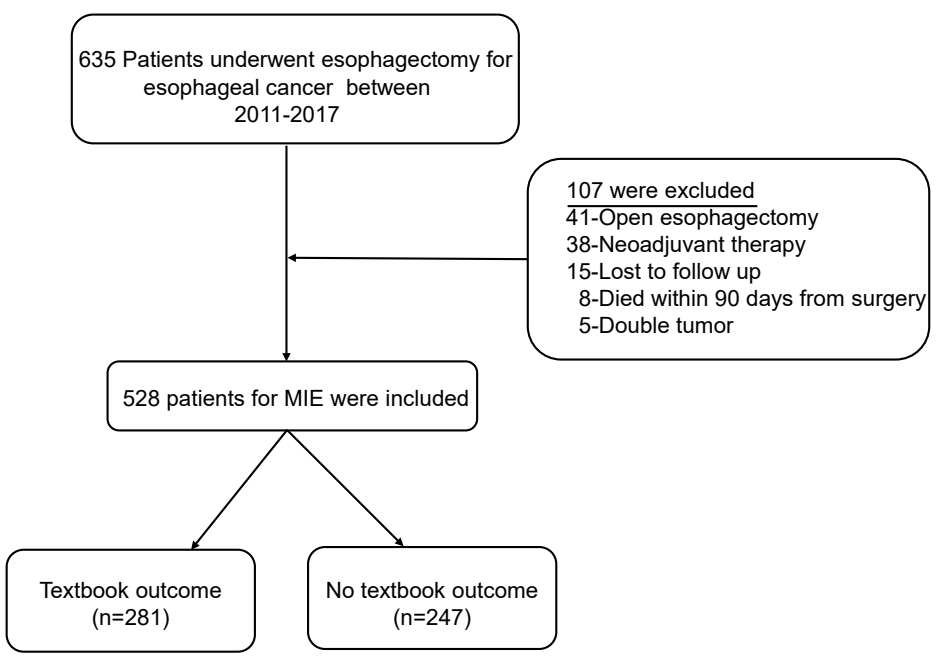

Figure S1 Flowchart of inclusion criteria for patients. MIE, minimally invasive esophagectomy. 
Table S1 Univariate and multivariate Cox analysis of clinicopathological factors for DFS

\begin{tabular}{|c|c|c|c|c|c|c|}
\hline \multirow{2}{*}{ Factors } & \multicolumn{3}{|c|}{ Univariate analysis } & \multicolumn{3}{|c|}{ Multivariate analysis } \\
\hline & $\mathrm{HR}$ & $95 \% \mathrm{Cl}$ & $P$ value & $\mathrm{HR}$ & $95 \% \mathrm{Cl}$ & $P$ value \\
\hline \multicolumn{7}{|l|}{ Period } \\
\hline 2011-2012 & Ref. & & & & & \\
\hline 2013-2014 & 1.034 & $0.737-1.452$ & 0.845 & & & \\
\hline 2015-2017 & 0.832 & $0.589-1.175$ & 0.297 & & & \\
\hline \multicolumn{7}{|l|}{ Age } \\
\hline$\leq 65$ & Ref. & & & & & \\
\hline$>65$ & 1.435 & $1.048-1.964$ & 0.024 & & & \\
\hline \multicolumn{7}{|l|}{ Sex } \\
\hline Female & Ref. & & & & & \\
\hline Male & 0.815 & $0.588-1.128$ & 0.218 & & & \\
\hline \multicolumn{7}{|l|}{ ASA score } \\
\hline I-II & Ref. & & & & & \\
\hline III-IV & 1.493 & $1.033-2.156$ & 0.033 & & & \\
\hline \multicolumn{7}{|l|}{$\mathrm{BMI}\left(\mathrm{kg} / \mathrm{m}^{2}\right)$} \\
\hline$\leq 18.5$ & Ref. & & & & & \\
\hline $18.5-25$ & 1.383 & $0.860-2.226$ & 0.181 & & & \\
\hline$\geq 25$ & 1.659 & $0.951-2.893$ & 0.075 & & & \\
\hline \multicolumn{7}{|l|}{ Tumor location } \\
\hline Proximal & Ref. & & & & & \\
\hline Mid & 1.426 & $0.838-2.426$ & 0.191 & & & \\
\hline Distal & 1.416 & $0.801-2.501$ & 0.231 & & & \\
\hline \multicolumn{7}{|l|}{ Histologic grade } \\
\hline $\mathrm{Gx} / \mathrm{G} 1$ & Ref. & & & & & \\
\hline G2 & 1.086 & $0.820-1.437$ & 0.566 & & & \\
\hline G3 & 1.189 & $0.733-1.929$ & 0.484 & & & \\
\hline \multicolumn{7}{|l|}{ TNM stage } \\
\hline I & Ref. & & & Ref. & & \\
\hline II & 2.232 & $1.389-3.587$ & 0.001 & 2.09 & $1.299-3.363$ & 0.002 \\
\hline III & 4.37 & $2.839-6.728$ & & 4.253 & $2.761-6.552$ & $<0.001$ \\
\hline IVA & 8.642 & $4.707-15.866$ & & 8.77 & $4.766-16.137$ & $<0.001$ \\
\hline \multicolumn{7}{|l|}{ Surgical procedure } \\
\hline McKeown & Ref. & & & & & \\
\hline Ivor Lewis & 0.825 & $0.543-1.252$ & 0.366 & & & \\
\hline \multicolumn{7}{|c|}{ Lymphadenectomy } \\
\hline Two-field & Ref. & & & & & \\
\hline Three-field & 0.823 & $0.536-1.261$ & 0.371 & & & \\
\hline \multicolumn{7}{|l|}{ Blood loss (mL) } \\
\hline$\leq 100$ & Ref. & & & Ref. & & \\
\hline $100-200$ & 1.18 & $0.883-1.578$ & 0.262 & 1.156 & $-0.863-1.547$ & 0.331 \\
\hline$\geq 200$ & 2.443 & $1.612-3.702$ & $<0.001$ & 2.382 & $1.559-3.637$ & $<0.001$ \\
\hline \multicolumn{7}{|l|}{ Smoking status } \\
\hline Never & Ref. & & & & & \\
\hline Current/former & 0.93 & $0.711-1.215$ & 0.593 & & & \\
\hline \multicolumn{7}{|c|}{ Adjuvant chemotherapy } \\
\hline No & Ref. & & & & & \\
\hline Yes & 1.288 & $0.984-1.686$ & 0.066 & & & \\
\hline \multicolumn{7}{|l|}{ TO } \\
\hline No & Ref. & & & Ref. & & \\
\hline Yes & 0.674 & $0.516-0.881$ & 0.004 & 0.756 & $0.576-0.992$ & 0.044 \\
\hline
\end{tabular}

DFS, disease-free survival; ASA, American Society of Anesthesiology; BMI, body mass index; TO, textbook outcome; $\mathrm{HR}$, hazard ratio; Cl, confidence interval. 
Table S2 Univariate and multivariate Cox analysis of clinicopathological factors for RFS

\begin{tabular}{|c|c|c|c|c|c|c|}
\hline \multirow{2}{*}{ Factors } & \multicolumn{3}{|c|}{ Univariate analysis } & \multicolumn{3}{|c|}{ Multivariate analysis } \\
\hline & $\mathrm{HR}$ & $95 \% \mathrm{Cl}$ & $P$ value & $\mathrm{HR}$ & $95 \% \mathrm{Cl}$ & $P$ value \\
\hline \multicolumn{7}{|l|}{ Period } \\
\hline 2011-2012 & Ref. & & & & & \\
\hline 2013-2014 & 0.907 & $0.616-1.336$ & 0.621 & & & \\
\hline 2015-2017 & 0.594 & $0.398-0.886$ & 0.011 & & & \\
\hline \multicolumn{7}{|l|}{ Age } \\
\hline$\leq 65$ & Ref. & & & & & \\
\hline$>65$ & 1.323 & $0.903-1.938$ & 0.151 & & & \\
\hline \multicolumn{7}{|l|}{ Sex } \\
\hline Female & Ref. & & & & & \\
\hline Male & 0.908 & $0.622-1.324$ & 0.615 & & & \\
\hline \multicolumn{7}{|l|}{ ASA score } \\
\hline I-II & Ref. & & & & & \\
\hline III-IV & 1.503 & $0.977-2.310$ & 0.063 & & & \\
\hline \multicolumn{7}{|l|}{$\mathrm{BMI}\left(\mathrm{kg} / \mathrm{m}^{2}\right)$} \\
\hline$\leq 18.5$ & Ref. & - & & & & \\
\hline $18.5-25$ & 1.503 & $0.829-2.726$ & 0.18 & & & \\
\hline$\geq 25$ & 2.01 & $1.022-3.953$ & 0.043 & & & \\
\hline \multicolumn{7}{|l|}{ Tumor location } \\
\hline Proximal & Ref. & & & & & \\
\hline Mid & 1.315 & $0.705-2.452$ & 0.39 & & & \\
\hline Distal & 1.465 & $0.755-2.841$ & 0.259 & & & \\
\hline \multicolumn{7}{|l|}{ Histologic grade } \\
\hline $\mathrm{Gx} / \mathrm{G} 1$ & Ref. & & & & & \\
\hline G2 & 1.175 & $0.837-1.649$ & 0.351 & & & \\
\hline G3 & 1.448 & $0.834-2.514$ & 0.189 & & & \\
\hline \multicolumn{7}{|l|}{ TNM stage } \\
\hline I & Ref. & & & Ref. & & \\
\hline II & 1.251 & $1.251-4.084$ & 0.007 & 2.347 & $1.256-4.386$ & \\
\hline III & 4.874 & $2.858-8.313$ & $<0.001$ & 5.182 & $2.896-9.273$ & $<0.001$ \\
\hline IVA & 9.922 & 4.833-20.369 & $<0.001$ & 11.166 & $5.249-23.752$ & $<0.001$ \\
\hline \multicolumn{7}{|c|}{ Surgical procedure } \\
\hline McKeown & Ref. & & & & & \\
\hline Ivor Lewis & 0.824 & $0.497-1.364$ & 0.451 & & & \\
\hline \multicolumn{7}{|c|}{ Lymphadenectomy } \\
\hline Two-field & Ref. & & & & & \\
\hline Three-field & 1.157 & $0.729-1.837$ & 0.536 & & & \\
\hline \multicolumn{7}{|l|}{ Blood loss (mL) } \\
\hline$\leq 100$ & Ref. & & & Ref. & & \\
\hline $100-200$ & 1.287 & $0.911-1.817$ & 0.152 & 1.197 & $0.842-1.702$ & 0.317 \\
\hline$\geq 200$ & 2.518 & $1.537-4.125$ & $<0.001$ & 2.065 & $1.235-3.451$ & 0.006 \\
\hline \multicolumn{7}{|l|}{ Smoking status } \\
\hline Never & Ref. & & & & & \\
\hline Current/former & 0.89 & $0.647-1.224$ & 0.474 & & & \\
\hline \multicolumn{7}{|c|}{ Adjuvant chemotherapy } \\
\hline No & Ref. & & & & & \\
\hline Yes & 1.482 & $1.070-2.051$ & 0.018 & & & \\
\hline \multicolumn{7}{|l|}{ TO } \\
\hline No & Ref. & & & Ref. & & \\
\hline Yes & 0.633 & $0.459-0.872$ & 0.005 & 0.71 & $0.512-0.985$ & 0.04 \\
\hline
\end{tabular}

RFS, Recurrence-free survival; ASA, American Society of Anesthesiology; BMI, body mass index; TO, textbook outcome; HR, hazard ratio; $\mathrm{Cl}$, confidence interval. 


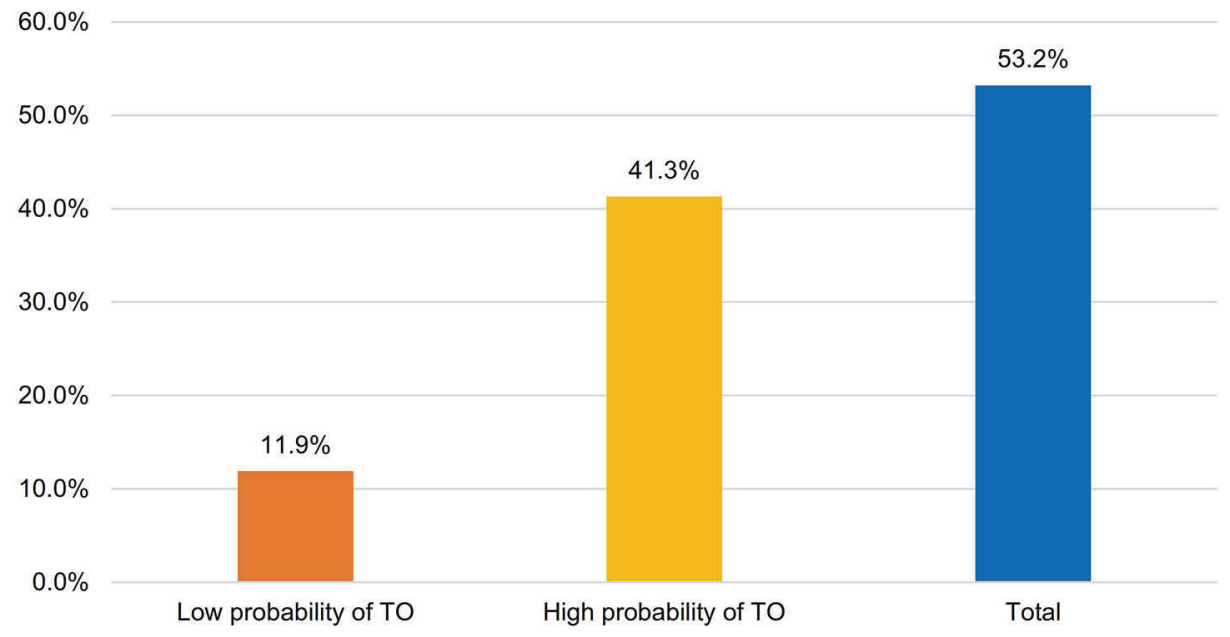

Figure S2 Nomogram prediction for the possibility of achieving TO. TO, textbook outcome. 